\title{
Canadian physicians frustrated with vaccine rollout
}

Cite as: CMAJ 2021 March 29;193:E458-9. doi: 10.1503/cmaj.1095929

Posted on cmajnews.com on March 11, 2021

anadian physicians are feeling increasingly anxious and fatigued as the coronavirus disease 2019 (COVID-19) pandemic wears on, with many citing frustrations over Canada's vaccine rollout as a factor.

In a Canadian Medical Association (CMA) survey of 1648 practising doctors, most reported feeling anxiety and fatigue about COVID-19 and said those feelings had increased since the beginning of the pandemic.

Asked about the factors negatively contributing to their mental health, $62 \%$ of 1561 respondents cited concerns about the vaccine rollout, as well as social restrictions (64\%) and uncertainty about the future (63\%).

Canada's approval of four COVID-19 vaccines is an encouraging light at the end of the tunnel, but "the tunnel is still long," says CMA President Dr. Ann Collins, a New Brunswick-based family physician.

Four in five physicians surveyed ranked coordinating Canada's vaccine distribution strategy as a top priority for improving the country's management of the pandemic.

However, three in five rated the federal government's ability to secure vaccine supplies as poor or very poor. Just over half gave equally bad marks to their provincial or territorial government's management of the vaccine rollout.

By contrast, nearly half of the doctors surveyed felt their provincial and territorial governments had done a good or excellent job following expert advice (46\%) and communicating about other public health measures (45\%). A similar proportion praised the federal government's financial support programs (44\%).

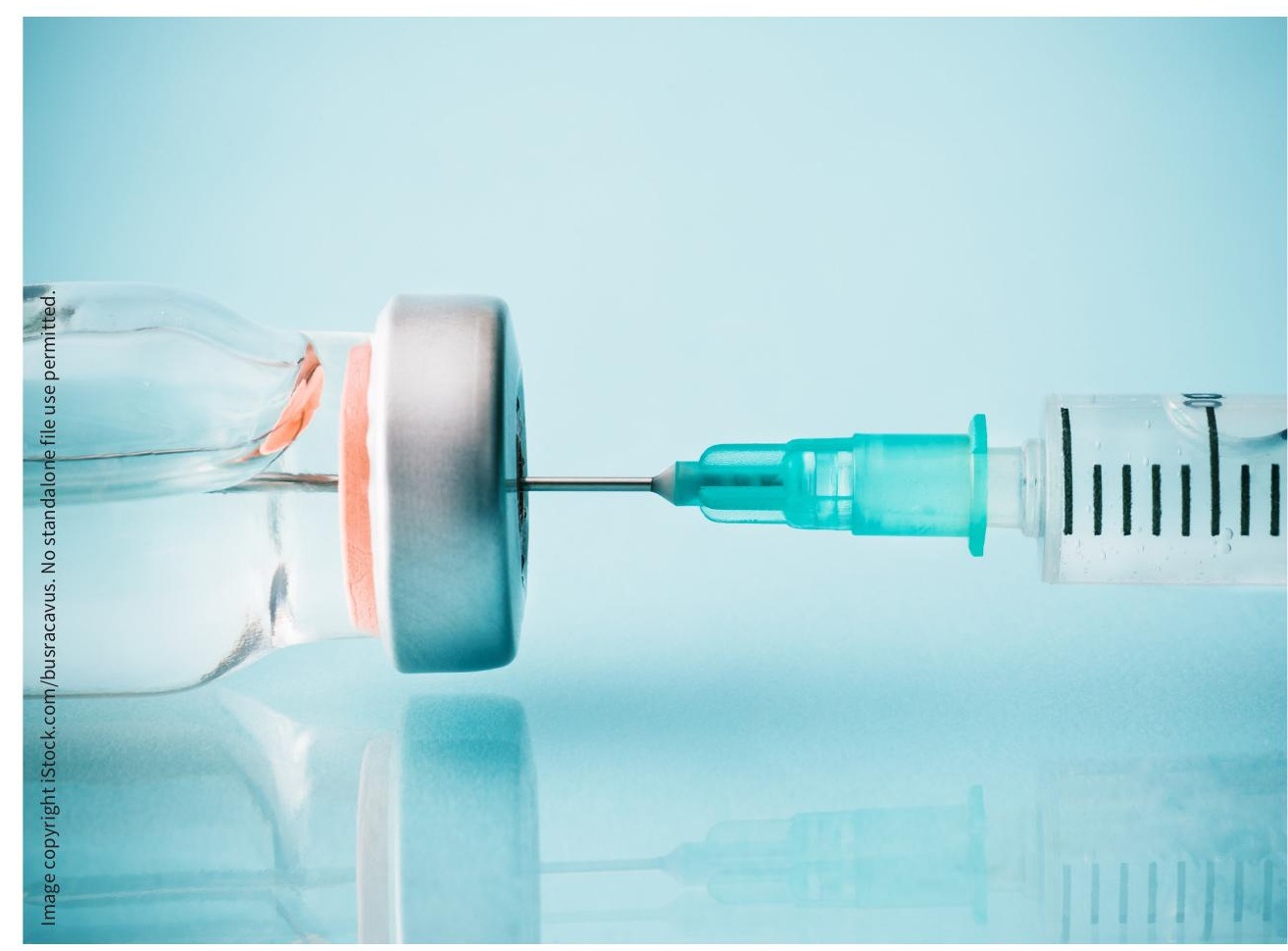

Three in five physicians surveyed by the Canadian Medical Association cited concerns about Canada's vaccine rollout as a stressor.

Nearly all the physicians surveyed (93\%) said the vaccine supply was a key challenge to the rollout in their province or territory. Some also had concerns about the clarity of directions on priority groups for vaccination (52\%) and the engagement of physicians in the vaccine rollout (39\%).

"We all know the cornerstone of any good relationship is clear communication, and I think that has been very frustrating for physicians," says Collins.

CMA didn't report demographic data on the survey respondents, so it's not possible to tell if the results are nationally representative.
However, delays in shipments of the Pfizer and Moderna vaccines have led to supply issues across the country, and patients have reported a wide range of barriers to vaccination, from language and mobility issues in British Columbia to booking system errors in Alberta and busy phone lines in Quebec.

Uncertainty and poor communication have led to some frustrating experiences in Ontario, too, says Dr. Jennifer Kwan, a family physician in Burlington.

In late February, the head of Ontario's vaccine task force told reporters that family doctors would soon be contacting patients over age 80 about vaccination - 
without informing doctors beforehand. The announcement led many patients to call their physicians the next business day, flooding phone lines and impeding access for patients calling for other reasons.

According to Kwan, many family doctors are willing to help with vaccine distribution or vaccine clinics but have not been told how.

"It's been very poor communication and very poor planning," says Dr. Sandy Tecimer, a Toronto-based community family physician. "There was a long time when we couldn't get vaccines, and they were distributed to hospitals, but there were communities in rural or Northern Ontario that didn't have any."

Tecimer notes some "non-patientfacing staff" in hospitals and nursing homes received COVID-19 shots before priority groups - ostensibly because the doses were close to expiring.

Meanwhile, some older people have trouble navigating vaccination phone lines and registration websites and are therefore left out. One of Tecimer's patients is 94 with a 75-year-old son - the current system is frustrating for them both. "It really is favouring people who are capable, able-bodied and computersavvy," she says.

Tecimer and others have petitioned Ontario's government to allow nursepractitioner-led clinics, communitybased family doctors and pharmacies to administer COVID-19 vaccines. She says these settings are more familiar and accessible to marginalized people in society, including people who are elderly.

Ontario announced on March 10 that it would offer the AstraZeneca vaccine to eligible people at 325 pharmacies and expand the rollout to more pharmacies as supplies increase.

\section{Diana Duong, CMAJ}

Content licence: This is an Open Access article distributed in accordance with the terms of the Creative Commons Attribution (CC BY-NC-ND 4.0) licence, which permits use, distribution and reproduction in any medium, provided that the original publication is properly cited, the use is noncommercial (i.e., research or educational use), and no modifications or adaptations are made. See: https://creativecommons.org/ licenses/by-nc-nd/4.0/ 